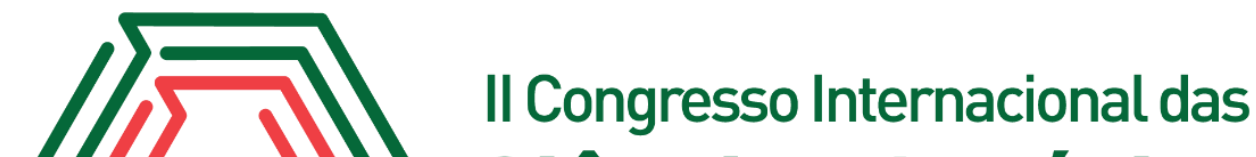 Ciências Agrárias COINTER - PDVAgro 2017
}

\section{LEVANTAMENTO FITOSSANITÁRIO DAS COMUNIDADES RURAIS DO NORDESTE PARAENSE}

Apresentação: Pôster

\begin{abstract}
Kerolém Prícila Sousa CARDOSO ${ }^{1}$; Jéssica Taynara da Silva MARTINS ${ }^{2}$; Vitor Resende do NASCIMENTO $^{3}$; Jackeline Araújo Mota SIQUEIRA ${ }^{4}$; Cândico Ferreira de OLIVEIRA NETO ${ }^{5}$
\end{abstract}

\section{Introdução}

A agricultura é uma das principais atividades econômicas no estado do Pará e serve como agente propulsor do desenvolvimento comercial e dos serviços e, embora sua maior intensidade agrícola esteja na região nordeste, diversos fatores ocorrem limitando o desenvolvimento dos cultivos, podendo-se destacar o ataque de fitopatógenos. Esses agentes fitopatológicos vêm causando grandes prejuízos nas principais culturas do Nordeste Paraense como no município de Capitão Poço-PA.

Este município tem base econômica fundada na agricultura e o citros e a pimenta-do-reino como principais produtos agrícolas considerados propulsores de fonte de renda para o agricultor da região, e que são extremamente afetados por patógenos que prejudicam a sua produção. Com isso, o objetivo deste trabalho foi realizar um levantamento fitossanitário das comunidades rurais no município de Capitão Poço-PA, a fim de orientar os produtores com possíveis alternativas para combater os problemas fitossanitários.

\section{Fundamentação Teórica}

No Estado do Pará, onde a citricultura exerce importante papel econômico e social, a

\footnotetext{
${ }^{1}$ Pós-graduação em Ciências Florestais, Universidade Federal Rural da Amazônia, Belém-PA, e-mail:

k.cardoso.agro@gmail.com

${ }^{2}$ Graduação em Agronomia, Universidade Federal Rural da Amazônia, Belém-PA, e-mail: jessicamartins1609@gmail.com

${ }^{3}$ Pós-graduação em Ciências Florestais, Universidade Federal Rural da Amazônia, Belém-PA, e-mail: vitoresf@gmail.com

${ }^{4}$ Professora, Drä., Universidade Federal Rural da Amazônia, Capitão Poço-PA, e-mail: jackeline.araujo@ufra.edu.br

${ }^{5}$ Professor, Dr., Universidade Federal Rural da Amazônia, Belém-PA, e-mail: candido.neto@ufra.edu.br
} 
produção de citros está concentrada principalmente na microrregião do Guamá, apresentando os municípios de Capitão Poço, Irituia e Ourém como principais produtores, formando o polo citrícola paraense e, assumindo posição de destaque na produção (Farias et al., 2012).

Assim, estudos que identifiquem os fitopatógenos são de suma importância à melhoria da produtividade e qualidade dos alimentos, uma vez que estes agentes causam danos às culturas, influenciando direta e indiretamente na rentabilidade do empreendimento agrícola com a redução da produção e limitação da quantidade e qualidade do produto (Michereff (2001).

\section{Metodologia}

A pesquisa foi realizada em 2014 em três comunidades do município de Capitão Poço-PA: Cubiteua; Nova Colônia e Capitão pocinho. Segundo a classificação de Koeppen, o clima da região é do tipo Ami com precipitação anual em torno de $2.500 \mathrm{~mm}$, e uma curta estação seca entre setembro e novembro (precipitação mensal em torno de $60 \mathrm{~mm}$ ), temperatura média de $26^{\circ} \mathrm{C}$ e umidade relativa do ar entre 75 á $89 \%$ (Schwart, 2007).

Foi aplicado um questionário contendo perguntas de cunho social e econômico, além de perguntas direcionadas a variáveis relacionadas à Fitossanidade: presença ou ausência de doenças, formas de identificação e tratamentos. Após obter as informações necessárias, consultaram-se literaturas com a finalidade de comparar de forma mais precisa e clara as doenças vistas em campo buscando medidas de tratamento adequadas ao controle desses fitopatogenos.

\section{Resultados e Discussões}

Em uma propriedade na comunidade de Cubiteua observou-se a presença da fumagina, doença causada por fungos do gênero Capnodium (Figura 1), que possuem micélio espesso recobrindo folhas, ramos e frutos, o qual em associação com cochonilhas produzem secreções escuras que podem revestir toda a planta com uma coloração negra podendo ser confundido com o principal agente causal do distúrbio: os insetos.

Uma poda de limpeza e o controle das cochonilhas são recomendações de controle. Outra medida de manejo agrícola é o controle químico da gomose, que de acordo com o trabalho de Feichtenberger et al. (1997), o controle químico realizado com os fungicidas sistêmicos fosetyl-Al e 
metalaxyl, apresentam comprovada eficácia no controle preventivo e curativo da gomose.

Figura 1. Fumagina em uma laranjeira na comunidade rural de Cubiteua, em Capitão Poço - PA.

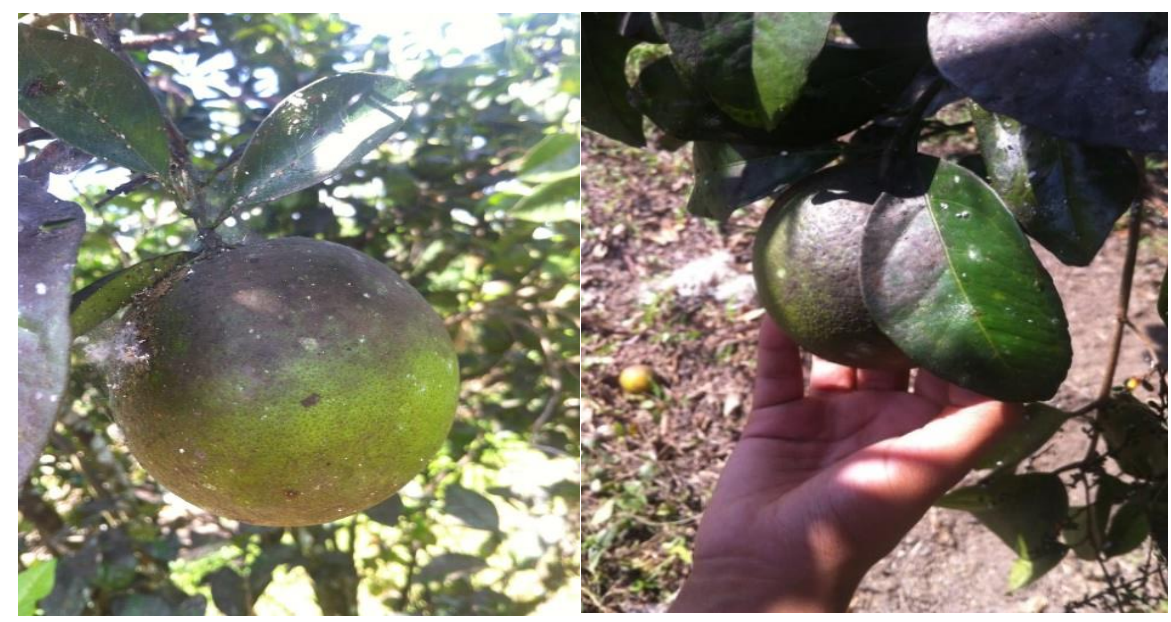

Fonte: Própria

Além da fumagina, observou-se a presença do abortamento floral dos frutos, uma doença mais conhecida como Estrelinha (Figura 2), sendo causada pelo fungo Colletotrichum acutatum que infecta os tecidos de flores e frutos jovens provocando a queda prematura dos frutos. A recomendação para o produtor controlar esse fitopatógeno é fazer a pulverização de maneira preventiva, ou seja, antes do sintoma da doença.

Figura 2. Estrelinha, observada em Cubiteua; Capitão-poço - PA.

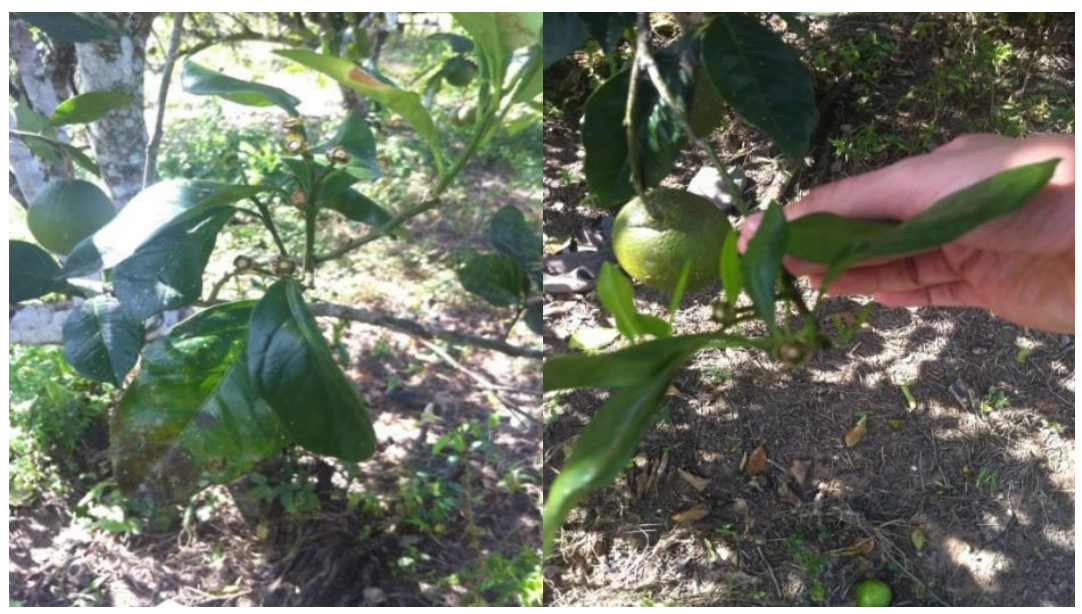

Fonte: Própria

Na comunidade de Nova Colônia o principal cultivo realizado é o da Pimenta-do-reino, sendo a fusariose (Figura 3) a doença que mais acomete esta cultura. Esta doença é causada por um fungo presente no solo, o Fusarium solani f. sp. Piperis, que praticamente ataca todas as partes da planta, causando uma grande perda ao produtor. O controle indicado para $F$. solani ainda é a 
prevenção, como o uso de mudas de alto padrão fitossanitário, o monitoramento em campo, a identificação e a erradicação das plantas sintomáticas (Silva et al., 2011).

O controle biológico é uma alternativa para o manejo, no qual Trichoderma spp. são utilizados como antagonistas de fungos fitopatogênicos mais estudados por apresentarem variabilidade em relação à atividade de biocontrole, espectro de ação contra hospedeiro, propriedades fisiológicas e bioquímicas, além da adaptação ecológica e ambiental (Ávila et al., 2005).

Figura 3. Fusariose, observada em um pimental na comunidade de Nova Colônia, em Capitão Poço - PA. Fonte própria.

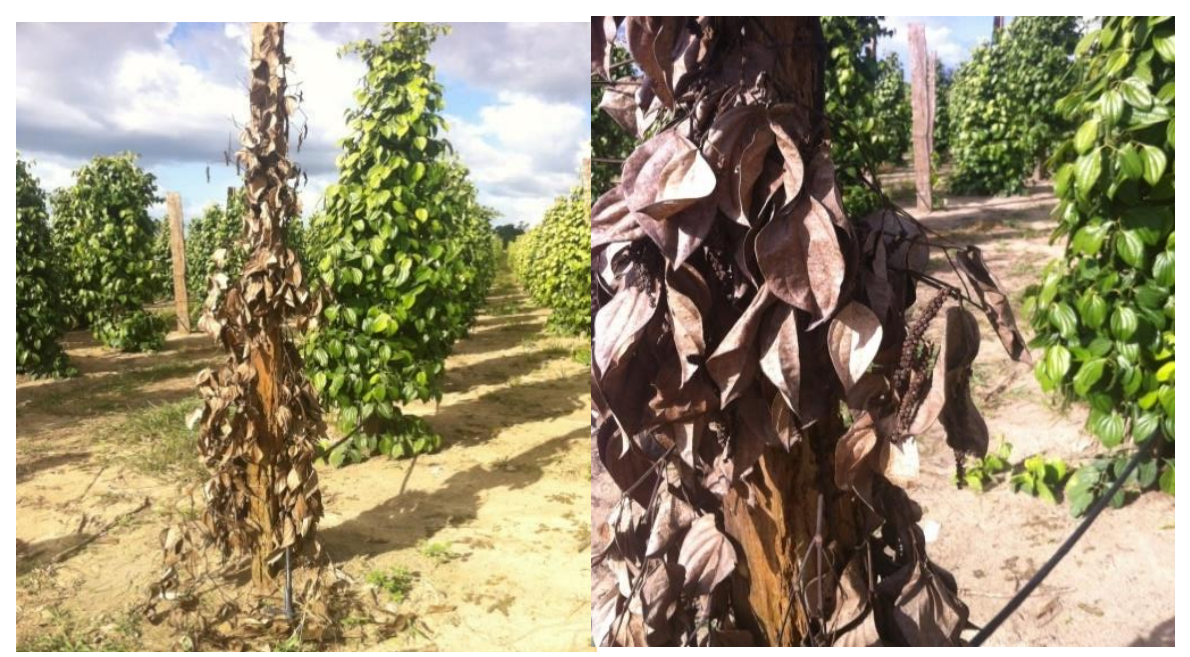

Fonte: Própria

Na comunidade de Capitão Pocinho foi realizada uma visita na empresa Citropar representando atualmente, a maior empresa produtora de cítricos do Norte e Nordeste do País. Embora na área tenham sido encontradas doenças como gomose, declínio e fumagina, a empresa recebe assistência técnica especial e imediata para que a produção não seja prejudicada, tendo o controle dos danos causados por essas doenças.

\section{Conclusão}

As comunidades visitadas necessitam de apoio técnico ao controle dos fitopatógenos, bem como medidas sociais voltadas ao seu desenvolvimento econômico. Portanto, é primordial uma delimitação mais abrangente de todas essas áreas afetadas e áreas vizinhas para buscar alternativas a fim de atenuar os prejuízos causados por doenças e/ ou pragas. 


\section{Referências}

ÁVILA, Z.R.; CARVALHO, S.S.; BRAÚNA, L.M.; GOMES, D.M.P.A.; SILVA, M.C.F.; MELLO, S.C.M.M. Seleção de isolados de Thichoderma spp. antagônicos a Sclerotium rolfsii e Sclerotinia sclerotiorum. Brasília: Embrapa Recursos Genéticos e Biotecnologia, 2005. 30p.

FEICHTENBERGER, E. Effect of systemic fungicides applications on growth responses and fruit yields of sweet orange trees in Phytophthora infested soil: gummosis of citrus with systemic fungicides in Brazil. In.: World Congress of The International Society o f Citrus Nurserymen , 5., 1997, Montpellier.267 - 279.

MICHEREFF, S. J. Fundamentos de Fitopatologia. Recife: Universidade Federal Rural de Pernambuco, 2001. 150 p.

SCHWART, G. Manejo sustentável de florestas secundárias: espécies potenciais no Nordeste do Pará, Brasil. Amazônia: Ciência \& Desenvolvimento, vol 3, 5ª ed, p. 125-147, 2007.

SILVA, B.S.O.; DRUMOND NETO, A.P.; SILVA, M.B. Pimenta-do-reino: importância da defesa fitossanitária para a sustentabilidade da atividade na região norte do Espírito Santo. Revista Brasileira de Agropecuária Sustentável (RBAS), Viçosa, MG, v.1, n.1, p.88-92, 2011.

FARIAS, P. R. S.; SILVA, A. G.; SILVA, J. B.; BRANDÃO, A. D. S.; SILVA, E. B. M.; BOIÇA JUNIOR, A. L. Dinâmica populacional de cochonilha-deplacas em pomares de citros em sistemas agroflorestal e monocultura. Revista de Ciências Agrárias. v. 55, n. 4, p. 269-276, out./dez. 2012. 